\title{
Entre el hábitat y la vivienda. Dos experiencias de organización comunitaria y cooperativa en la ciudad de Rosario (Argentina)
}

Pagnoni, Anahí G.

Profesora y licenciada en Historia por la Universidad Nacional de Rosario (UNR). Docente jefa de Trabajos Prácticos en la cátedra Espacio y Sociedad de las carreras de Historia y Antropología de la Facultad de Humanidades y Artes (UNR). Becaria doctoral del CONICET. IECH-CONICET-UNR anahipagnoni@hotmail.com

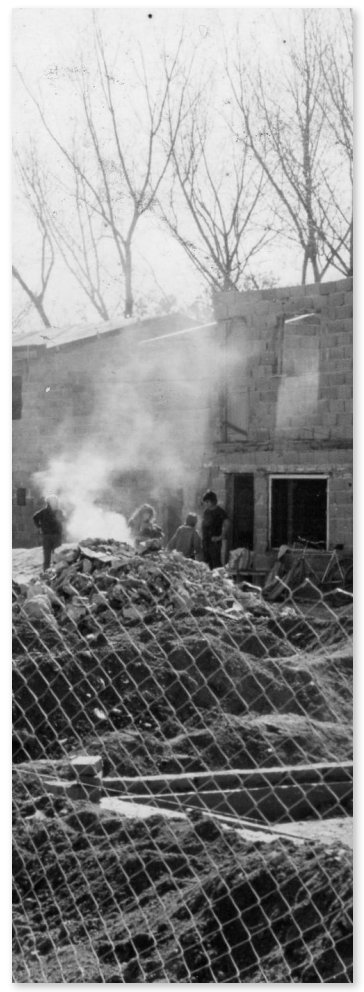

http://dx.doi.org/10.30972/crn.31315780 
Entre el hábitat y la vivienda.

Dos experiencias de organización comunitaria y cooperativa en la ciudad de Rosario (Argentina)

\section{Resumen}

El presente artículo estudia la experiencia de dos cooperativas de vivienda, ubicadas en la zona sur de Rosario, durante la década del 80. El objetivo de este trabajo será indagar cómo estas organizaciones se vincularon con la implementación de las políticas alternativas del hábitat, aplicadas por el Estado a nivel nacional, a inicios de los 90 . En principio, se reseñará el proceso de transformación de las políticas habitacionales nacionales, influidas por el paradigma del hábitat a nivel internacional; luego, se explorará en cada uno de los casos presentados el modo de organización cooperativa, los vínculos con otras instituciones y el contacto con el Municipio. Finalmente, se analizarán tanto los cambios en la relación de las agrupaciones y el Estado como las transformaciones en el interior de la organización cooperativa que ocasionaron la implementación de estas políticas.

\section{Palabras clave}

Vivienda social; hábitat; cooperativa; políticas habitacionales; periferia.

\section{Between habitat and housing. Two experiences of community and cooperative organization in the city of Rosario (Argentina)}

\section{Abstract}

This article studies the experience of two housing cooperatives, located in the southern area of Rosario city, during the 1980s. The objective of this work is investigate how these organizations were link to the implementation or alternative habitat policies, applied by the State at the national level, in the early 1990s. In principle, the transformation process of national housing policies will be reviewed, influenced by the paradigm of habitat at the international level; then, the cooperative organization mode, the links with other institutions and the contact with the Municipality will be explored in each of the cases presented. Finally, both the changes in the relationship between the groups and the State and the transformation inside the cooperative organization that generated the implementation of this policies will be analyzed.

\section{Key words}

Social housing; habitat; cooperative; housing policies; periphery.
Entre habitat e habitação.

Duas experiências de organização comunitária e cooperativa em a cidade de Rosario (Argentina)

\section{Resumo}

Este artigo estuda a experiência de duas cooperativas habitacionais, localizadas na zona sul da cidade de Rosario, durante a década de 1980. O objetivo deste trabalho é investigar como essas organizações se vincularam à implementação de políticas de habitats alternativos, aplicadas pelo Estado no âmbito nacional, no início dos anos 90. Em princípio, será revisado o processo de transformação das políticas habitacionais nacionais, influenciado pelo paradigma do habitat em nível internacional; a seguir, serão explorados, em cada um dos casos apresentados, o modo de organização cooperativa, as ligações com outras instituições e o contato com o Município. Finalmente, serão analisadas as mudanças nas relações entre as agrupações e o Estado e as transformações dentro da organização cooperativa que levaram à implementação dessas políticas.

\section{Palavras-chave}

Habitação social; habitat; cooperativa; políticas habitacionais; periferia. 
Desde los años 80, las políticas alternativas de vivienda o de la segunda generación (CuENYA \& Falú, 1997; Cravino, 2012; Zapata, 2017), implementadas por el Estado argentino, repercutieron en el modo de acceso a la vivienda y al suelo urbano para los sectores populares. Estos usuarios adquirieron un conjunto de nuevas prácticas sociales y políticas para la gestión de su hábitat que produjo una modificación en sus vínculos con el barrio y la ciudad misma. No obstante, al establecerse el dispositivo de gobierno neoliberal, durante la década siguiente, esta maquinaria estuvo poco dispuesta a entregarle "todo el poder al usuario", como había postulado JoHn TuRner (1977) en su clásico trabajo sobre autoconstrucción. El acceso al suelo urbano se encontraba - y se encuentra - restringido para los menos favorecidos en las urbes contemporáneas (Del Río, 2011).

La búsqueda de un lugar en la ciudad plasma los términos que el Estado impone como sistema jurisdiccional. Ante esta situación, el principal interés de las organizaciones barriales ha sido generar espacios de apertura, donde negociar, luchar y trabajar por su derecho a la vivienda y a la ciudad.

Para analizar la implementación de las políticas alternativas de hábitat en Rosario, la presente propuesta abordará la experiencia de dos agrupaciones barriales ${ }^{1}$ que conformaron sus cooperativas de vivienda con este paradigma habitacional (SALGADO, 2012; MarTínez NoRIEGA,1994). Ambas organizaciones emergieron en espacios periféricos contiguos, ubicados en la zona sur de la ciudad, durante los 80. Por un lado, la Cooperativa de Vivienda de Villa Margarita se originó con el trabajo barrial de los vecinos de esa villa miseria, localizada en uno de los márgenes del arroyo Saladillo y próxima al río Paraná. Por otro lado, la Asociación Civil el Monte representaba el asentamiento informal del mismo nombre que ocupaba una porción de los terrenos del Parque Regional Sur. Sin equiparar las particularidades de cada entidad, ambas recibieron apoyo de ONG o de otras instituciones civiles para sus proyectos habitacionales.

Más allá de estos casos particulares, cabe destacar que los problemas urbanos de los asentamientos informales rosarinos se manifestaron con mayor fuerza en los 90. En 1989, los saqueos de alimentos en supermercados y pequeños comercios, suscitados por la crisis inflacionaria y la inestabilidad política del gobierno, habían expuesto las condiciones de vida de la población más vulnerable de la ciudad (Dalla Corte, 2014). Si durante la década del 80 la crisis económica obstaculizó el diagnóstico de la crisis urbana, con el cambio de
1. El presente trabajo cuenta con entrevistas en profundidad a algunos miembros de la cooperativa de vivienda y a los vecinos del barrio. Los nombres de los protagonistas y los espacios han sido modificados para impedir su identificación. 
década, esta última era incuestionable. Principalmente en el sur de la ciudad, donde habían estallado los disturbios, la preeminencia del problema habitacional apareció junto con los reclamos por la penuria económica (PAGNONI, 2019). Asimismo, el cambio de partido político en el gobierno municipal, el relevo del radicalismo por el socialismo (1989-1994), coincidió con la implementación de nuevas prácticas gubernamentales de intervención, destinadas a los ciudadanos afectados por la emergencia alimentaria. Entre esas prácticas, la Municipalidad actuó como mediadora y facilitadora de subsidios y de proyectos de vivienda que se ejecutaron como parte de las nuevas políticas de hábitat (CARNÉ, 2016).

A partir de la experiencia de las cooperativas de vivienda y de los cambios municipales post-saqueos (1989-1994), el objetivo de este trabajo será problematizar cómo se incorporó “el paradigma del hábitat” y se gestionaron las políticas de vivienda de la segunda generación en Rosario. El principal interés es problematizar de qué manera estas agrupaciones barriales que se habían constituido con el apoyo de organizaciones civiles, luego, ingresaron en la esfera estatal y se beneficiaron de ciertos planes y subsidios nacionales. Ante estos interrogantes, en el primer apartado, se expondrán los cambios y las continuidades de esas nuevas políticas, enfatizando cómo el Estado las administró y transformó el lugar de los usuarios. En el segundo y el tercer apartado, se profundizará en los derroteros de cada una de las organizaciones. Allí, se problematizarán tres cuestiones:

- la primera: cómo lograron reunirse las agrupaciones barriales;

- la segunda: de qué modo estas instituciones gestionaron la autoconstrucción de sus viviendas y con quiénes se conectaron para ello y

- la tercera: en el marco de las nuevas políticas de vivienda, qué relación entablaron las cooperativas con el Municipio.

Para abordar la experiencia cooperativa de las organizaciones, se recurrió a dos metodologías. Por un lado, en el caso de Villa Margarita, el acercamiento etnográfico fue posible por mi colaboración semanal en las actividades del centro comunitario de la cooperativa, todavía en funcionamiento. Este contacto me concedió un espacio para realizar entrevistas en profundidad y confeccionar un diario de campo sobre mi colaboración allí, durante dos años. La participación en el trabajo barrial se desarrolló entre noviembre de 2015 y diciembre de 2017. Este recurso aportó un registro de las vivencias de sus pobladores, quienes compusieron una memoria colectiva de su práctica autoconstructiva, apoyada en una polifonía de voces. Por otro lado, en el caso de la organización vecinal del asentamiento 
El Monte, la disolución de su cooperativa de vivienda dificultó realizar entrevistas a sus protagonistas. Esto implicó recurrir a una metodología hermenéutica para la reconstrucción de la experiencia. Para ello, se relevaron diferentes medios de comunicación, principalmente los diarios de la ciudad La Capital y Rosario 12, y se construyó un corpus discursivo sobre la problemática.

La expropiación de los terrenos del Parque Regional Sur, cedidos a la Asociación Civil para regularizar su situación dominial, desató una disputa con los vecinos del barrio de Saladillo, quienes se negaban al sacrificio del espacio público para esos fines. La prensa local cubrió detalladamente el conflicto, reproduciendo, incluso, las opiniones de sus protagonistas en primera persona. Cabe destacar que el trabajo de campo en Villa Margarita me permitió conocer el caso de la Vecinal el Monte y su lucha barrial, ya que ambas organizaciones conformaron el Movimiento Social Hábitat Popular. El interés en emplear ambos recursos para la propuesta metodológica se justificó en la posibilidad de generar acercamientos a la problemática que contemplen un modo plural de abordarla y enriquezcan, a través de la comparación y contrastación de experiencias, nuestra mirada sobre el hábitat popular en Rosario. En ese camino, se ensayará una aproximación a estas experiencias que subraye el rol de los sectores populares en la implementación de las políticas alternativas de hábitat en la ciudad.

\section{Un acercamiento a las políticas alternativas argentinas del hábitat}

Con la recuperación democrática (1983), las políticas de vivienda argentinas adquirieron nuevos lineamientos para afrontar el problema urbano que significaba la proliferación de las villas miserias y los asentamientos irregulares. Por un lado, la influencia del nuevo paradigma del "hábitat", difundido por los organismos de crédito internacional, postulaba intervenciones en esos lugares para incorporar a sus habitantes a las tramas urbanas (CRAvino, 2012). Esto propició el cese de las erradicaciones y los traslados forzosos que habían caracterizado, en parte, el modus operandi del gobierno dictatorial (1976-1983). Esto ocurría, principalmente, cuando esas poblaciones impedían proyectos de modernización urbana o se ubicaban en terrenos con valorización inmobiliaria (Cravino, 2006). Por otro lado, en el interior del Estado, las políticas de vivienda comenzaron a flexibilizarse, incorporaron nuevos actores y descentralizaron ciertas funciones hacia las provincias (BALLENT \& LIERNUR, 2014). Particularmente, los planes del Fondo Nacional de Vivienda (FONAVI, en adelante), 
2. Aunque excede a este artículo, la autora propone una tercera generación de políticas habitacionales que se desarrolló luego de la crisis de 2001 (ZAPATA, 2017, p. 79). la mayor línea de crédito para "vivienda social", se encontraron afectados por estas transformaciones. La incorporación de las cooperativas de vivienda y los preceptos de la "ayuda mutua" a sus líneas de crédito influyeron en la paulatina asimilación del paradigma del hábitat en las políticas del gobierno argentino (CuENYA, 1997).

A partir de estos cambios, María Cecilia Zapata (2017) ha identificado dos generaciones de políticas para abordar el "problema de la vivienda" ${ }^{2}$. En la primera generación de políticas habitacionales (1950-1980), la construcción masiva de viviendas sociales ganó importancia creciente y consolidó las instituciones del Estado de Bienestar (CRAvino et AL., 2002). A pesar de que la vivienda era un tema de debate político e intervención estatal, el gobierno peronista (1945-1955) lo incorporó a la agenda pública al aumentar el número unidades terminadas. La gestión centralizada de esta política se sostuvo a través de los créditos otorgados por el Banco Hipotecario Nacional (BHN, en adelante), que adquirió un fuerte protagonismo como ente financiero de aquella. Asimismo, el cambio en el modo de abordar la cuestión habitacional condicionó las acciones de los próximos gobiernos, que no pudieron ignorarla ni evitar destinarle recursos (BALLENT \& LIERNUR, 2014).

Los principales beneficiarios de estas medidas habían sido las clases medias y los trabajadores sindicalizados, aunque, durante los años 60, el crecimiento de las villas miseria en las periferias urbanas provocó que se incorporaran programas específicos para atender estas situaciones. Conceptualmente, la vivienda masiva se reemplazó con la vivienda de interés social, ampliando el involucramiento estatal y abarcando a los sectores más desfavorecidos de la sociedad (BALLENT \& LiERNUR, 2014). Estas políticas con una férrea gestión centralizada y verticalista proyectaban conjuntos habitacionales realizados por grandes empresas constructoras y entregados "llave en mano" a sus adjudicatarios.

El FONAVI ha sido significativo en el interior de estos programas, porque sobrevivió al cambio de paradigma de la vivienda social al hábitat que se instauró en la transición a la segunda generación de políticas de habitacionales, durante la década del 80 . El programa se había creado en 1972, pero sus planes de vivienda no se efectivizaron hasta 1977. Con tipologías de tira o torre, estos megacomplejos habitacionales son popularmente conocidos como "barrios FONAVI" por la ruptura que su morfología causa en la trama urbana. A pesar de representar la expresión arquitectónica más vanguardista en materia de diseño para la vivienda llave en mano, su aplicación era tardía para las evaluaciones de los organismos 
internacionales. En el momento de la implementación del FONAVI, estos organismos consideraban obsoletas las políticas de financiación de la oferta y, en su lugar, fomentaban las propuestas habitacionales con participación de la población (CuENYA, 1997).

Sin embargo, los cambios de gobernabilidad que las dictaduras de los 1970 impusieron en Argentina y Latinoamérica explican, en parte, la continuidad de estos planes. En este punto BEATRIZ CUENYA (1992) ha aportado una interesante hipótesis para pensar la subsistencia de estas políticas del Estado Benefactor. Para la autora, la marcada contradicción entre la aplicación de un programa ortodoxo de estabilización de la economía que definió el rumbo neoliberal del gobierno dictatorial y el mantenimiento del gasto público en la política habitacional solo se explicaba por la dimensión político-social que propició el Estado burocrático-autoritario (O’DonnelL, 1976). En efecto, se trataba de un poder represivo que imponía por la fuerza sus decisiones sobre la sociedad civil. Por lo tanto, era lo suficientemente autónomo para generar intereses propios y abrir espacios de negociación con determinados sectores de la burguesía. Así, el Estado burocrático-autoritario atendió los beneficios de ciertos sectores de la industria de la construcción y de las burocracias públicas, que con la ejecución de estos complejos de vivienda ejercían un control financiero sobre el propio Estado (CuenYa, 1992). Esto explicaba la perdurabilidad de un modelo de política habitacional divergente con respecto a los lineamientos del neoliberalismo reinante.

Asimismo, cabe contemplar que la construcción de estas viviendas de interés social produjo un ordenamiento particular de las periferias urbanas, al menos en Argentina. El interés de la dictadura era estimular el mercado inmobiliario, afín con los primeros desarrollos de una economía política neoliberal y las empresas constructoras que la apoyaban. Como efecto, los megacomplejos de vivienda concentraban a la población que no contaba con los suficientes recursos económicos para ingresar en el mercado de la vivienda. La creciente crisis económica y el abandono estatal ocasionaron la paulatina degradación de estos enclaves, que incorporaron su morfología a las periferias urbanas estigmatizadas. En este proceso, quizás, pueda percibirse un efecto - poco evidentede fragmentación urbana que las políticas neoliberales de la dictadura produjeron en los bordes de la ciudad. Es decir, la propia morfología de los complejos de vivienda, súper-manzanas aisladas, generaba una ruptura de la trama urbana que, combinada con la política autoritaria y la crisis económica, anclaba territorialmente a su población en esos espacios, cada vez más segregados. 
3. La Coalición Internacional del Hábitat (HIC) organizó tres conferencias HABITAT en Vancouver 1976, Estambul, 1996 y Quito, 2016.
Estas medidas no se sostuvieron en la transición democrática argentina a comienzos de los años 80. La insolvencia financiera de los planes FONAVI en su funcionamiento interno (CuenYa \& FaLú, 1997) se conjugó con la crisis de la deuda externa -derivada del alza en las tasas de interés internacional- que el Estado debió afrontar. Esta reestructuración del capitalismo a nivel mundial afectó las democracias emergentes de Argentina y Latinoamérica. Su endeudamiento las obligó a implementar políticas de ajuste en todos los campos de la vida social como respuesta a los organismos de crédito. En medio de este conflicto, la incorporación del paradigma del hábitat a las políticas de vivienda nacionales se alineó con los cambios económicos internacionales.

En esta senda, las ideas de JoHn Turner (1977) acerca de los pobladores como protagonistas del proceso urbano, tras su investigación de la urbanización espontánea en las barriadas de Lima (Perú), colaboraron en crear una nueva línea de trabajo y promoción de la vivienda popular. Asimismo, su relevancia se relacionaba con su participación en el movimiento internacional UNO-HABITAT (HIC SG, 2016). Esta organización, nucleada en la Coalición Internacional del Hábitat, ha tenido - y continúa teniendo - como propósito el desarrollo sostenible de los asentamientos humanos (villas miseria, en Argentina). Su trabajo se inició en la Conferencia de Naciones Unidas en Asentamientos Humanos, también denominado Hábitat I (Vancouver, 1976) ${ }^{3}$. Allí se destacó la importancia de preservar el patrimonio construido en estos asentamientos, garantizar la seguridad de tenencia de la tierra para sus pobladores y proveer la infraestructura básica a esos sitios (Cravino, 2012). Este conjunto de iniciativas se conoció mundialmente como "políticas alternativas de vivienda", y se distinguió de las viejas políticas que ofrecían unidades habitacionales terminadas.

Los preceptos teóricos del hábitat se propagaron en Latinoamérica, no solo por la recomendación de organismos internacionales como las Naciones Unidas, sino a través de la financiación de estos. Bajo el paradigma internacional de "integración y radicación", se materializaron ciertas experiencias de mejoramiento de asentamientos en la región, solventadas por organismos multilaterales de crédito, como el Banco Mundial o el Banco Iberoamericano de Desarrollo (BID, en adelante) (Cravino, 2012). La ayuda económica se conectaba con una de las recomendaciones principales del HABITAT I, "fomento de las cooperativas para la vivienda, la infraestructura y los servicios" (HIC SG, 2016, p. 9). Así, muchas experiencias se centraron en la regularización dominial de los tugurios y la construcción de hogares para sus pobladores en pequeña escala. Pero, también, el lugar otorgado a las organizaciones 
comunitarias como interlocutoras generó una creciente relación entre estas y ciertas iniciativas la sociedad civil, grupos profesionales u ONG que consolidaron su participación en la causa habitacional como actores de relevancia creciente (VITALE, 2013).

La eclosión de la crisis inflacionaria argentina, en 1989, ocasionó una masiva protesta social, popularmente conocida como los saqueos ${ }^{4}$, que aceleró la transformación definitiva al neoliberalismo del Estado ${ }^{5}$. Con el achicamiento del Estado (OszLAK, 1993), el FONAVI, última trinchera de las políticas asistenciales del Estado Benefactor, se desarticuló como sistema centralizado a nivel nacional. En su lugar, algunas de sus funciones - y un menor presupuesto- se atribuyó a cada uno de los Institutos de Vivienda de las provincias y sus municipios (CuenYA \& FaLÚ, 1997). Esto colaboró en producir una política habitacional más "territorializada", en la cual los Municipios adquirieron un marcado protagonismo para su implementación (ZAPATA, 2017).

En sintonía con el nuevo paradigma internacional del hábitat, el Estado Nacional implementó Las políticas de promoción y solidaridad con los más necesitados (1990), que apuntaban a la solución de problemas específicos. Entre ellas, uno de los programas más relevantes en materia de vivienda era el Plan Arraigo ${ }^{6}$, que otorgó la titularidad dominial a villas y asentamientos que se afincaban en terrenos fiscales (las dos organizaciones rosarinas presentadas aquí regularizaron sus locaciones con estas medidas). A través de la mediación de los gobiernos locales, el Programa Arraigo cedía a las cooperativas, organizadas para mejorar las condiciones de habitación de sus miembros, la propiedad de los espacios que ocupaban irregularmente en la ciudad. En este sentido, las secretarías de planificación urbana municipal, alineadas con las propuestas de regeneración del entorno, argumentaban que la mayor seguridad en la tenencia de la tierra repercutiría en mejoras edilicias de los hogares de los barrios populares (CUENYA, 1997).

Estas medidas, las políticas alternativas de vivienda -o la segunda generación de políticas habitacionales - se transformaron en uno de los modos de gestión del problema habitacional, a principios de los años 90. A través de subsidios puntuales, sus programas argumentaban atender dos falencias históricas en materia de vivienda. Con la ayuda financiera, se pretendía subsidiar las realidades desatendidas: sin techo, villeros, inquilinos pobres, loteos clandestinos y autoconstructores en lotes
4. Para un estudio detallado de este acontecimiento, ver: DI MEGLIO, G. Y SERULNICOV, S. (2017), La larga historia de los saqueos en la Argentina: De la independencia a nuestros días, Buenos Aires: Siglo XXI Editores.

5. Como lo explica LöIc WAQCUANT: "el neoliberalismo es un proyecto político trasnacional que articula la relación entre el Estado, el Mercado y la ciudadanía desde arriba. La promoción del mercado y el desarrollo del capital se fusionan con un conjunto de lógicas institucionales: desregulación económica, el ideal cultural de la responsabilidad individual, y un aparato penal expansivo, instructivo y proactivo" (WAQCUANT, 2010, p. 430).

6. En 1992, se creó la Comisión Nacional de Tierras Fiscales, dependiente de la Presidencia, como órgano aplicador de la Ley Nacional de Tierras (Ley $\left.N .^{\circ} 23.967\right)$ para ejecutar el Programa Arraigo, de regularización dominial de tierras, mejoramiento barrial integral y urbanización de asentamientos informales, lotes con servicios, conformación de bancos de tierra, microcréditos para estímulo a la vivienda progresiva, e intervenciones de pequeña escala con distintos tipos de articulación sectorial. 
propios. Y, a la vez, se buscaba por medio de las cooperativas de vivienda y de trabajo incentivar la participación de los sectores populares en la economía, ya que el sector concentrado de la construcción se había desplazado hacia otros rubros con mayor rentabilidad (ZAPATA, 2017).

El cambio más significativo en la aplicación de estas políticas fue el nuevo rol del Estado Nacional en ellas. El Estado se había desempeñado como regulador del mercado inmobiliario a través de la financiación y el desarrollo de sus planes. Con la descentralización de la operatoria FONAVI, se desplazó de ese lugar. Pero las políticas centralizadas no dejaron de existir ni de incorporar sus viviendas sociales al mercado del suelo. Cecilia Marengo y Ana Laura Elorza (2016) analizaron el proceso insularización y segregación residencial que la ubicación periférica de las soluciones habitacionales provocó en el espacio urbano de la ciudad de Córdoba durante los 90. En consonancia con ello, se considera que, si bien la dictadura no modificó los lineamientos de las políticas "llave en mano" del Estado Benefactor, su aplicación en un clima económico neoliberal repercutió en la producción de una espacialidad urbana fragmentada que profundizó la polarización de las ciudades argentinas en las décadas siguientes.

La masificación de la vivienda en una ciudad dinámica pero carente de puestos de trabajo para los sectores populares impacta en el ascenso de la valorización de nuevos espacios a la trama urbana. Es decir, en principio, estos sitios marginales pueden no valorizarse en el mercado inmobiliario, pero al ser parte del suelo urbano regularizado, la misma dinámica financiera los puede promocionar como nuevas centralidades.

En paralelo, las políticas alternativas habilitaron al Estado Nacional como un nuevo agente del juego del mercado que compartía o intercambiaba sus funciones con otras esferas gubernamentales y los organismos de crédito internacional. Juan Pablo Del Río (2011) ha planteado que este "giro neoliberal" del Estado configuró su (re)alineación hacia las medidas neoliberales de acceso al hábitat mediante el reemplazo del "intervencionismo estatal" por la "estrategia facilitadora", y bajo las recomendaciones prescriptas por las agencias internacionales. La solidaridad internacional y las limitadas intervenciones del Estado impactaban en un espacio urbano que se encontraba dominado por el mercado financiero. En este sentido, es significativo que estos programas otorgaran la propiedad de la tierra a villas y asentamientos, a través de la mediación de las cooperativas de vivienda y los gobiernos locales, formalizando la legalidad de la ocupación de los sectores 
populares. Al parecer, la regularización dominial a través de las políticas alternativas de hábitat, al igual que las soluciones habitacionales terminadas, se incorporaban a la lógica especulativa del mercado inmobiliario.

Sin embargo, esta política demandó de sus usuarios, las organizaciones populares localizadas en toda la geografía nacional, una estrategia propia de articulación con diversos actores sociales y políticos de proximidad. Con este objetivo, los sectores populares recurrieron a múltiples tácticas de trabajo y de lucha barrial que les permitieron la construcción de sus hogares. Dado lo focalizado de la aplicación de los programas nacionales, los Municipios aparecieron como mediadores entre estos y las agrupaciones barriales para garantizar el cumplimiento de los objetivos habitacionales. En los próximos apartados, se analizarán las modulaciones y formas de este proceso observando la experiencia de dos cooperativas de vivienda en la ciudad de Rosario.

\section{Autoconstrucción y lucha cooperativa en los márgenes del arroyo}

La Cooperativa de vivienda de Villa Margarita se fundó en febrero de 1989, aunque —según el relato de los propios vecinos—su organización barrial había comenzado en 1985. Esta villa miseria era un desprendimiento de un tugurio más antiguo, La Bajada, ubicado en la costa del río Paraná y lindero con el frigorífico Swift. A principios de los 80, con motivo de la construcción del Acceso Sur, el gobierno militar erradicó a los vecinos y los trasladó a otro barrio. En estas circunstancias, algunos resistieron el traslado forzoso y se instalaron a unos 500 metros de la obra vial. Así nació Villa Margarita, ubicaba sobre el brazo norte del arroyo, al oeste del Acceso Sur y más próxima a la grilla regular del Barrio de Saladillo. A pesar de las medidas autoritarias, con el retorno democrático, los vecinos erradicados lentamente volvieron a instalarse en La Bajada, sobre la costa del río. Un espacio vacío en la ribera les permitió (re) construir sus viviendas precarias y retornar a su principal actividad laboral: la pesca.

Entre 1986 y 1989, los vecinos de ambas villas, junto a militantes de izquierda que trabajaban en el barrio, identificaron los problemas que los aquejaban. Principalmente, ellos registraron el desempleo y la precariedad de sus hogares, sumados a la ausencia de infraestructura urbana básica. Por esta causa, la organización barrial se vinculó con otras experiencias cooperativas y habitacionales. 
Un pariente de una vecina de La Bajada, que volvía del exilio, se instaló en el barrio buscando trabajo. Se trataba de Julio, quien sería el vicepresidente de la primera comisión de la cooperativa. Una vez afincado, se involucró con los problemas que había en los asentamientos, recuperando su antigua militancia en la pastoral cristiana y su cercanía a la Teología de la Liberación. Así, retomó el vínculo con sus antiguos compañeros que habían regresado a la actividad política en el Movimiento Social "Hábitat Popular".

Este fue el primer contacto de los pobladores con el Movimiento Hábitat Popular para plantear las demandas habitacionales del área e inaugurar la ruta hacia el cooperativismo. En distintos pasajes de las entrevistas, los actores aludían a la dimensión internacional del movimiento "Hábitat Popular". Por ello, se sostiene que una parte de sus ideas se alineaban con las del movimiento habitacional internacional UNO-HABITAT. Asimismo, las cooperativas conforman un organismo internacional, la Alianza Cooperativa Internacional (ACI, en adelante), que es la institución más antigua reconocida por Naciones Unidas (PAIVA, 2008). En el interior del concierto de organismos internacionales, la ACI comparte con los movimientos de ONU-HABITAT la misma filiación vinculada con los organismos mundiales de crédito.

Mandamos el proyecto, lo hicimos nosotros a la vivienda sin tener en cuenta la parte técnica. Vos sabes que al mes vino una delegación de la MISERIOR de Alemania, vino de prepo, vinieron a ver... y querían hablar con nosotros... Ojo que vino con el cura, vino con una delegación de los que estaban acá. Y caminaron la villa, vos sabes, y se compadecieron de nosotros en las condiciones de la villa... La Bajada... montículo de basura, y más de escombro (entrevista con Julio, 20/08/2016).

Con la ayuda del movimiento "Hábitat Popular" y la mediación de la iglesia local, la cooperativa había logrado el contacto con MISERIOR, una ONG internacional, que otorgaba créditos a cooperativas de vivienda. Según los documentos de difusión de la cooperación alemana, MISERIOR como ONG conformaba una de las cuatro áreas de fomento de la Cooperación bilateral de la República Federal de Alemania. Específicamente, se orienta a la "autoayuda de las organizaciones no gubernamentales" en el sector de vivienda popular. Esta entidad se alinea con los dos principales organismos promotores de la cooperación multilateral en el sector de vivienda. Por un lado, las Naciones Unidas, a través de la organización especializada ONU-HABITAT, en el sector de cooperación técnica. Por otro, el 
Banco Mundial, en el sector de la cooperación financiera, junto a los bancos de desarrollos regionales (Ziss \& LEMKE, 1988). MISERIOR es una organización de ayuda de la iglesia católica alemana que persigue la contribución solidaria contra la miseria y la búsqueda de las estructuras sociales más justas en los países en vías de desarrollo, según sus propios medios de difusión (Ziss \& LEMKE,1988). Este objetivo se sustenta con la entrega de contribuciones financieras para la producción de vivienda popular a organizaciones que contemplen una estrategia de desarrollo comunitario.

Luego de esta visita y con la cooperativa recién inaugurada, MISERIOR concedió el crédito para construir las primeras catorce viviendas. El diseño y asesoramiento técnico para la edificación estuvo a cargo de la Universidad Nacional de Rosario (UNR). A través de un proyecto comunitario, la Facultad de Arquitectura y la de Ciencias Exactas, contactadas por los militantes de izquierda que colaboraban en el barrio, acompañaron la construcción de las viviendas. No fueron casuales las coincidencias de filiaciones con UNO-HABITAT de la ONG que financiaba y el Movimiento Hábitat Popular que lo gestionó. Este tipo de agencias de crédito internacional otorgaban recursos monetarios a proyectos habitacionales híper localizados, como sugerían las políticas alternativas de hábitat.

Al tratarse de una villa miseria, la entrega del subsidio por MISERIOR volvió a poner en escena el problema de la propiedad de la tierra, si bien los terrenos donde se ubicaba Villa Margarita sobre los márgenes del arroyo habían entrado en el "Plan Lote" (ley de Afecciones o Ley de Expropiaciones N. 9982). En 1986, esta normativa no había solucionado el problema de la propiedad. El plan provincial contemplaba la expropiación de tierras ocupadas por villas miseria, pero Villa Margarita se asentaba sobre dependencias del Ferrocarril Argentino General Belgrano (FCGB, en adelante), de propiedad nacional, que imposibilitó efectivizar la regularización dominial. Además, una ordenanza municipal prohibió la edificación de viviendas en las proximidades del arroyo y el río, por tratarse de zonas inundables (Ordenanza Municipal N. ${ }^{\circ}$ 4557). Según la ordenanza, los terrenos de Villa Margarita y La Bajada no eran aptos para la edificación por las posibilidades de derrumbe. Ambos contratiempos retrasaron el comienzo de las obras de la cooperativa, aunque ya habían recibido el subsidio de la ONG.

Sin embargo, la sanción del Plan Arraigo canalizó las gestiones realizadas por estos vecinos de Rosario en el marco del plan provincial. Así, la cooperativa concluyó su largo camino 


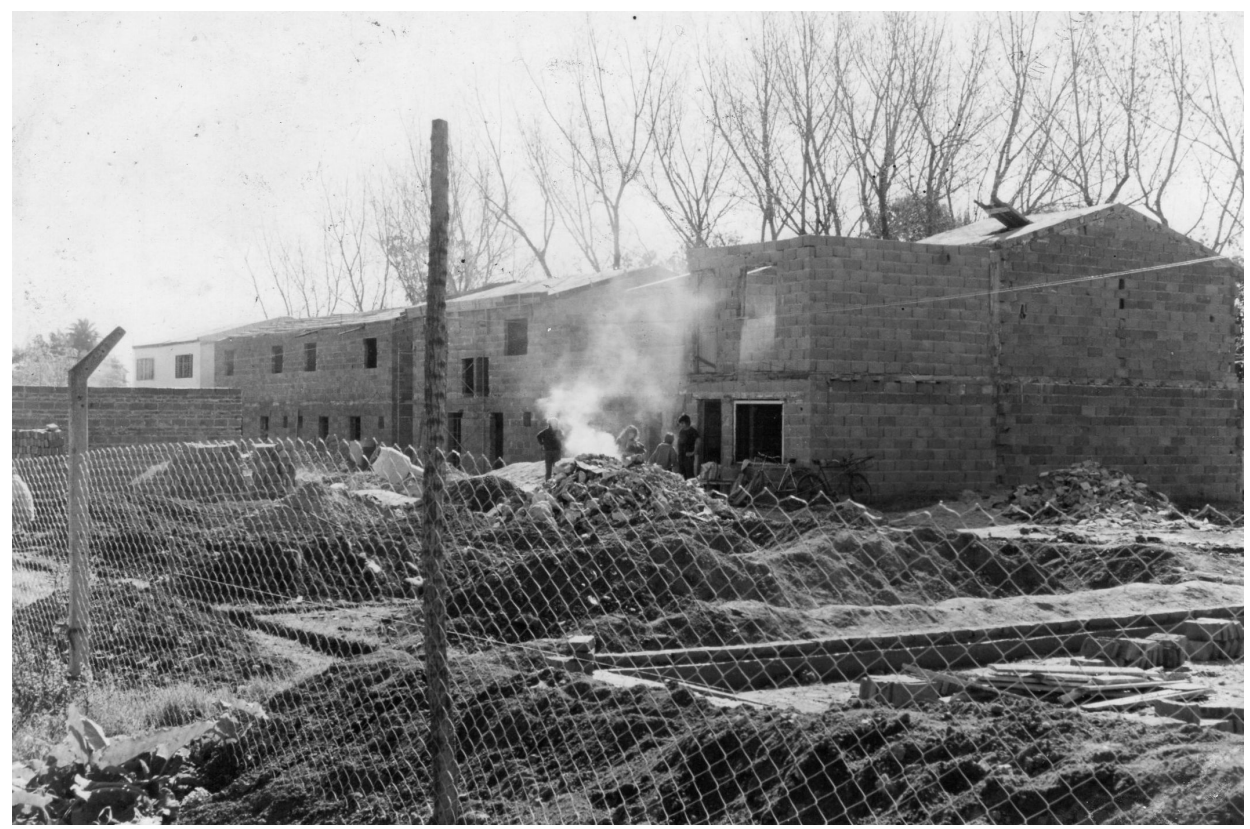

Figuras 1 y 2. Autoconstrucción de las viviendas 1990-1992. Fuente: Cooperativa de Vivienda

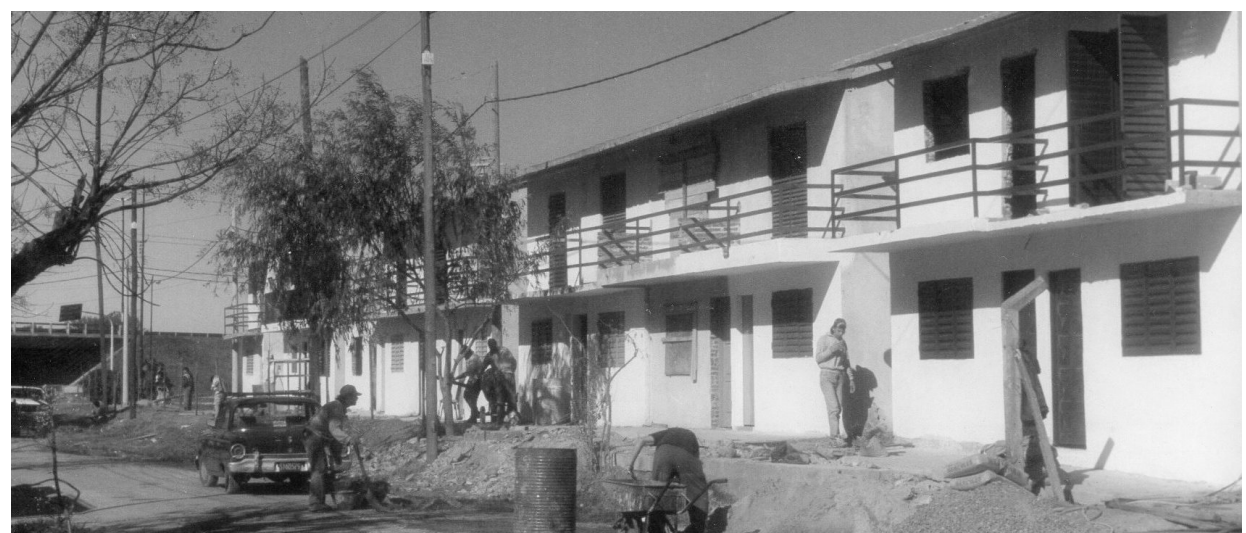


burocrático hacia la obtención de la propiedad de la tierra en 1993. El 20 de junio en el edificio municipal, el presidente en ejercicio, Carlos Menem, entregó a los vecinos el título de propiedad cooperativo de los terrenos donde avanzaba la construcción de las viviendas (La Capital, 21/06/1993). Más allá de cada derrotero particular, el Programa Arraigo podría pensarse como una política que recuperó las prácticas cooperativas y autogestivas que se habían realizado en la década anterior (MERKLEN,1997). En este sentido, se subraya cómo la transformación del Estado, producto de la crisis social y económica de 1989, profundizó los lineamientos de los organismos de crédito internacionales. Estos se habían difundido desde la década precedente, pero el contexto conflictivo determinó su definitiva implementación en las políticas de la segunda generación.

Para Marta, ese acto fue un momento muy importante. No solo se trató de un reconocimiento al trabajo que su marido (Manuel, presidente de la cooperativa), también es el único de sus recuerdos que ocurrió fuera de Villa Margarita. Ella conserva una foto borrosa de ese momento, y mientras me la mostraba, me contó entre risas que lo abrazó a Menem cuando fue al acto (entrada diario de campo, 15/02/2016).

Ante estos cambios, la Municipalidad de Rosario adquirió una participación más activa en las propuestas de hábitat. Del mismo modo, a los miembros de la cooperativa de Villa Margarita se les habilitó un canal de diálogo con el Municipio para gestionar y resolver los problemas propios del proceso constructivo. Esto se evidenció con la regularización de los terrenos del Programa Arraigo, que involucró a los expertos estatales para dirimirlo. En un acuerdo entre la Secretaría de Cooperativas, la Secretaría de Planificación y la comisión cooperativa, se decidió el traslado de las futuras viviendas al otro lado del brazo norte del arroyo, en un angosto terraplén del ex Ferrocarril General Belgrano. Su nueva ubicación las conectaba con el Barrio de Saladillo, a través de una de sus avenidas principales. No obstante, los terrenos eran estrechos y limitados; solo las familias de Villa Margarita, unas 50, comenzaron a construir las primeras viviendas.

Las consideraciones técnicas de la Secretaría de Planeamiento contemplaban la ordenanza de 1986 que detallaba los problemas topográficos de los terrenos cercanos a los cursos de agua, afectados por las inundaciones. Aunque con su cumplimiento, una parte de los integrantes de la cooperativa, las casi 100 familias de La Bajada, quedaron fuera del proyecto cooperativo por la supuesta ausencia de espacio urbano donde construir sus viviendas. Si bien en las entrevistas las diferentes autoridades de la cooperativa explican que estos 
vecinos, "los de abajo", no poseían la misma predisposición para la autoconstrucción como "los de arriba", o sea ellos, fueron los expertos municipales quienes determinaron hasta dónde llegaba la política alternativa de vivienda (DeL Río, 2011).

Paradójicamente, la implementación de las políticas neoliberales de hábitat, en este caso, reafirmó el efecto de las políticas dictatoriales respecto de estas villas miseria, cuando La Bajada había sido dividida y erradicada para construir el Acceso Sur. La separación de esta trama barrial, que se había subsanado con el trabajo colectivo de los vecinos, se reavivó, ya que, al ingresar la cooperativa en el programa de vivienda, se encontró obligada a cumplir los requisitos solicitados por el Estado. A partir de 1994, la segunda etapa del Plan Arraigo entregó subsidios para la construcción de viviendas a algunas de las cooperativas rosarinas que habían recibido la titularidad de la tierra en la etapa anterior. Villa Margarita obtuvo este incentivo, junto con otros entregados por el gobierno provincial, y concretó el proyecto de otras 51 viviendas en 2001.

\section{Vecinos y villeros. Una disputa habitacional en el Parque Regional Sur}

El asentamiento El Monte se localizaba en el límite suroeste del Parque Regional Sur, dividido en dos sectores. El primero de ellos se ubicaba bordeando el límite oeste del parque sobre las antiguas vías del FCGB. Desde allí, el segundo sector se extendía en dirección perpendicular al parque por una avenida, a lo largo de dos manzanas sobre la grilla regular (AA. VV.,1992). A inicios de los 80, sus primeros ocupantes se instalaron sobre los antiguos terrenos del ferrocarril, linderos al parque. Ante la difícil situación económica, ocasionada por la falta de trabajo y la precariedad habitacional e infraestructural de su entorno, los habitantes del asentamiento comenzaron a organizarse. Con la participación de una ONG local y la Municipalidad, se introdujeron en los problemas del hábitat y la vivienda popular, porque uno de sus objetivos era regularizar la propiedad de las tierras del asentamiento. Asimismo, el desempleo ocasionaba que la mayoría de los vecinos recibiera alguna de sus comidas diarias en el comedor municipal del barrio (Martínez Noriega,1994). Por ello, la agrupación se interesó en transformar esta instalación preexistente en un centro comunitario donde ampliar su trabajo barrial.

Con la colaboración del Centro Rosario de Estudios y Asesoramientos Técnicos para la Sociedad (CREATS, en adelante), una ONG local, los vecinos comenzaron la (re)construcción del 
comedor municipal. Para obtener los fondos necesarios de esta obra, se preveía un acuerdo entre la Municipalidad, la universidad y el BHN, que no logró concretarse. En estas circunstancias, CREATS se responsabilizó de la asignación de las responsabilidades y los fondos, interviniendo como mediadora entre la comunidad, la Municipalidad y el equipo técnico (Martínez Noriega, 1994). Para medidos de 1988, los trabajos de transformación del centro comunitario se encontraban a cargo de un grupo de los vecinos. Este colectivo, también, fundó la "Asociación Civil El Monte", lo que consolidó su inserción barrial. Aunque la incipiente agrupación se había incorporado al Movimiento Hábitat Popular, la irrupción de los saqueos paralizó sus actividades de mejora del centro comunitario y el afianzamiento en autoconstrucción de los vecinos. La organización dedicó todos sus recursos a centralizar la ayuda de emergencia, distribuyendo alimentos entre sus miembros.

Los cambios en el gobierno municipal, el reemplazo de Horacio Usandizaga (UCR, 1983-1989) por Héctor Caballero (PS, 1989-1994) también afectaron la continuidad de las reformas en el centro comunitario. Al parecer, el nuevo gobierno municipal se desvinculó de su participación por no coincidir con la filiación política de esta organización. Más allá de las motivaciones partidarias, se identifica un cambio en la relación con los barrios, luego de los saqueos (PAGNonI, 2019). En acuerdo con los señalamientos de Roberto Martínez Noriega (1994), se subraya una transformación en los modos de gestión que la Municipalidad aplicó en la periferia con el relevo del gobierno socialista. En efecto, durante la gestión radical, las intervenciones barriales se realizaban por requerimientos puntuales, en actividades y con recursos concretos. No existía una política planificada con anterioridad, sino que se entablaba una relación "administrativa" para resolver los problemas. Con la llegada del gobierno socialista, la relación con los sectores populares adquirió una política "estratégica". La Municipalidad se presentó preocupada por brindar una mayor atención a la problemática vecinal y construir un canal orgánico de comunicación con la periferia. El creciente afianzamiento de este marco repercutió en el papel de mediador que adquirió el municipio - y sus sucesivos intendentes socialistas-. Este rol se evidenció, principalmente, en la captación de los programas y los créditos habitacionales de diversos organismos nacionales (gobiernos provincial y nacional) e internacionales (ONG, BID, Banco Mundial) para organizaciones barriales como la presentada aquí (CARNÉ, 2016).

A pesar de esto, en junio de 1991, el Centro Comunitario El Monte se inauguró con un equipamiento básico. Ante la ausencia de apoyo estatal, la institución continuó con su función de comedor, trabajando con la ONG local, e incorporó talleres para los vecinos para ampliar su oferta de actividades. La consolidación de la Asociación Civil, a través de su diálogo 


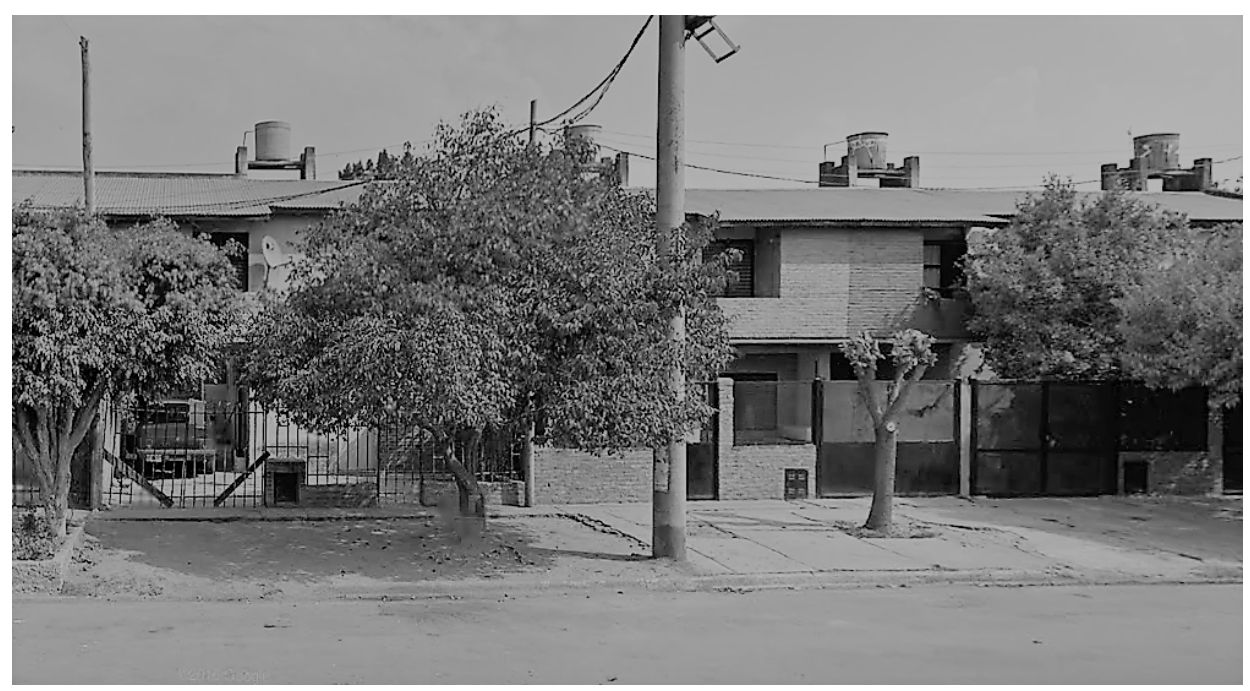

Figura 3. Primera etapa de viviendas (1999) para traslado de familias del Parque Sur. Fuente: Municipalidad de Rosario, 2017

con otras instituciones y con movimientos sociales como Hábitat Popular, demostró su importante trabajo barrial. Paulatinamente, se retomó el vínculo con la Municipalidad, que instaló una unidad sanitaria en el centro comunitario a fines de 1992 (La Capital, 20/08/1997).

En todo este proceso, el asentamiento creció y se extendió con más de 250 familias (AA. VV.,1992), que evidenciaron la urgencia en atender el problema habitacional. En 1993, en consenso con el gobierno provincial y la Municipalidad, la Asociación Civil El Monte y la recién creada Cooperativa de Vivienda La Gloria adquirieron la titularidad de los terrenos en el Parque Regional Sur con el Programa Arraigo (La Capital, 21/06/1993). No obstante, cuando en 1994 ambas organizaciones recibieron otro subsidio del Plan Arraigo para construir sus viviendas, se desencadenó un conflicto con los otros habitantes del barrio de Saladillo. 
Entre el hábitat y la vivienda. Dos experiencias de organización comunitaria y cooperativa en la ciudad de Rosario (Argentina)

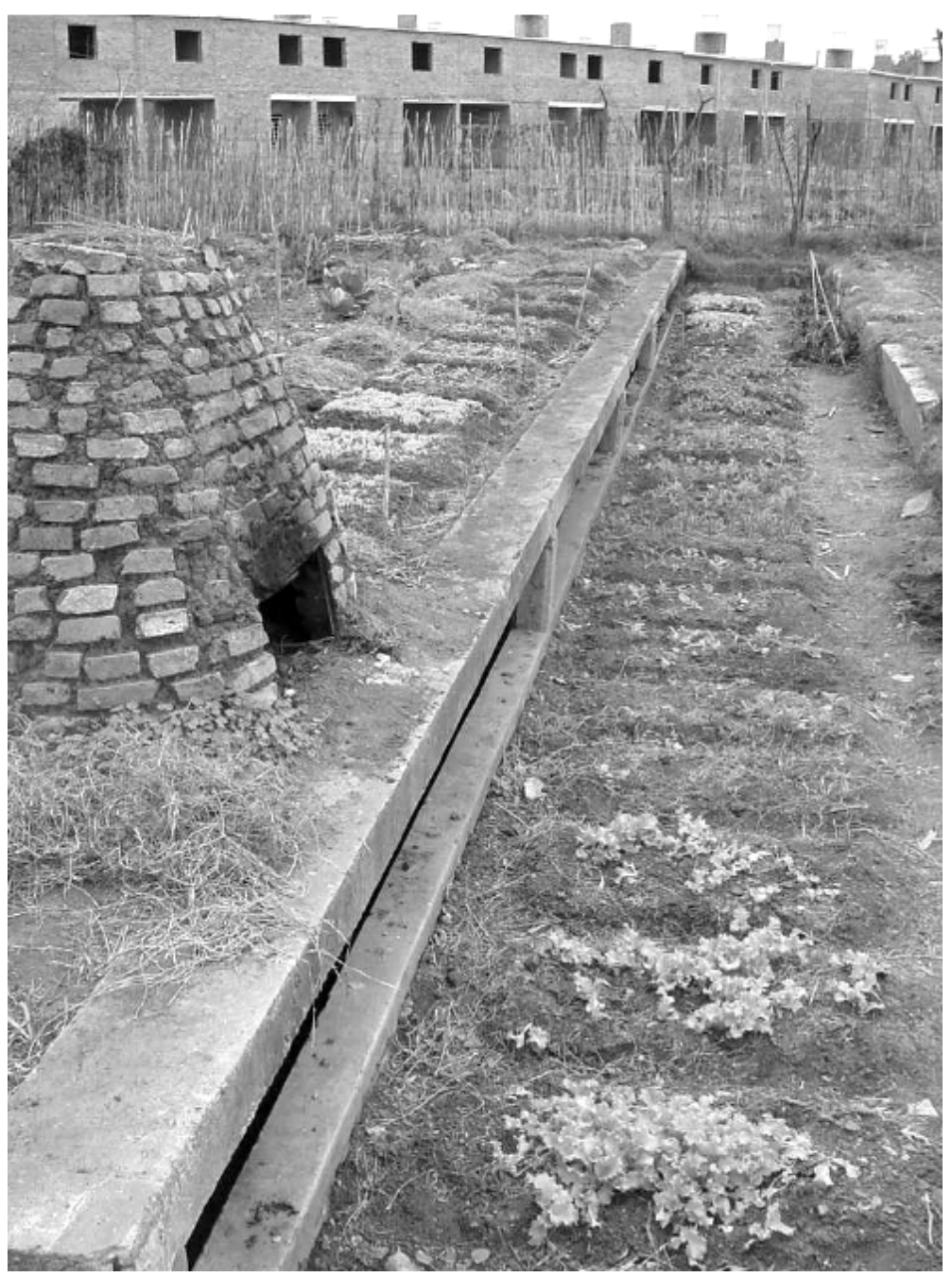

Figura 4. Sexta

etapa de viviendas

(2005). Fuente:

SALGADO, 2012 
7. El Parque Regional Sur se había inaugurado en 1973 por el gobernador Sylvestre Begnis para proteger el paisaje del arroyo Saladillo. En 1997, la provincia de Santa Fe efectivizó la cesión de los terrenos del parque a la Municipalidad de Rosario (35 hectáreas) y de San Nicolás (90 hectáreas), acordado por

la Ley 11.317 de 1995. Con esa transferencia este espacio público adquirió el nombre de Parque Sur Sylvestre Begnis.
La creciente oposición de los "vecinos" a la construcción de las viviendas quedó encubierta bajo un fuerte argumento ecologista y recreativo sobre el espacio público en cuestión. Así, las vecinales Saladillo y Saladillo Sud, la Asociación de Amigos del Parque Sur y un conjunto de organizaciones civiles del barrio se manifestaron para mostrar su descontento. En diferentes ocasiones, realizaron una sentada en Peatonal Córdoba (en el área central de la ciudad); también juntaron firmas contra "la privación que sufría la ciudad de este espacio público" y organizaron un festival por el "Día del Medioambiente" con bandas invitadas en el parque (La Capital, 17/05/1994, 4/06/1994, 15/07/1994). En su discurso, las autoridades vecinales afirmaban que no estaban en contra de los "villeros", sino que, cumpliendo con lo proyectado por el Plan Regulador Rosario (1991), solicitaban se respetara la construcción de la nueva entrada del parque y las viviendas sociales se trasladaran a otro lugar. En efecto, un miembro de la Vecinal Saladillo Sud explicaba la postura de los "vecinos" a la prensa:

Acá la única villa está sobre la calle H... Esta ubicación arruina el ingreso al parque por A... Me pregunto quiénes permitieron ese asentamiento en semejante lugar. No hay vecinos que estén a favor de la construcción del barrio en el Parque. Además, este barrio tiene una aceptable cantidad de vida para nosotros y para nuestros hijos. Verdaderamente sería un fraude que hagan esas viviendas (La Capital, 16/05/1994).

Como el Parque Regional Sur ${ }^{7}$ se encontraba bajo la potestad provincial, la Dirección Provincial de Vivienda y Urbanismo (DPVyU, en adelante) había propuesto afectar diez hectáreas de este para la construcción de las viviendas. Este proyecto se apoyaba en la ausencia de uso e infraestructura recreativa en esa zona (La Capital, 16/05/1994). Ante estos argumentos, los "vecinos" del barrio de Saladillo manifestaron su desacuerdo con las protestas arriba mencionadas. Cabe aclarar que los terrenos en cuestión, donde se ubicaba el asentamiento El Monte en el límite suroeste del parque, habían pertenecido al FCGB. Esta área se había incorporado al espacio público con la privatización del ente de transporte, un año antes (La Capital, 03/05/1992). Su situación jurisdiccional posibilitó conceder la propiedad colectiva de la tierra a las organizaciones barriales por medio del Plan Arraigo. En efecto, la gestión del DPVyU cumplía con las disposiciones de ese programa, cuyo mecanismo legal era la expropiación de tierra fiscal para la regularización de situaciones habitacionales como la descripta. 
Sin embargo, a la fuerte protesta de los "vecinos" se incorporó la intervención municipal, que argumentó la imposibilidad de edificación sobre los terrenos en disputa, ya que se encontraban sobre un gasoducto (La Capital, 17/05/1994). Ante estos impedimentos, la Municipalidad planteó un proyecto alternativo de traslado de las viviendas del asentamiento a un terreno aledaño al parque en su límite oeste. Según el plan, este nuevo espacio, a unas seis cuadras del asentamiento original, se anexaría con cuatro hectáreas (de las diez hectáreas afectadas por el proyecto provincial) que se encontraban en el extremo sur del parque, lo que brindaría la extensión suficiente para construir las 250 unidades habitacionales. Con este proyecto, la Municipalidad atendía el objetivo implícito de desocupar el espacio para la nueva entrada del parque y contentar los reclamos de los "vecinos" de Saladillo, quienes solicitaban mejoras urbanas para el espacio recreativo y el barrio.

Luego de varias asambleas entre los representantes del gobierno municipal y provincial y los pobladores de Saladillo, vecinos y villeros, todos acordaron ejecutar el proyecto alternativo de la Municipalidad. En estos encuentros, un miembro de la Asociación Civil El Monte describía la situación de los pobladores del asentamiento:

De todas maneras, nosotros aceptamos el otro lugar porque está a seis cuadras. No queríamos irnos más lejos porque la mayoría de nosotros trabajaba en la industria de la carne y los chicos van a la escuela de acá (...) Tenemos 4300 dólares de subsidio para vivienda del Banco Mundial, y alrededor de 15.000 de la provincia. No vamos a hacer ranchos, sino casas residenciales (Rosario $12,16 / 06 / 1994)$.

En junio de 1994, por un acuerdo tripartito del Estado nacional, provincial y municipal, el Servicio Público de la Vivienda, ente local de hábitat, entregó la propiedad pluripotencial de los nuevos terrenos a las organizaciones barriales (Ordenanza N. $\left.{ }^{\circ} 5924\right)$. Las diferentes partes también se comprometieron a garantizar la liberación del espacio para la nueva entrada al parque, cuando se concluyera la edificación de las viviendas (La Capital, 21/07/1994). A través de la financiación de diversos subsidios y el apoyo de los organismos de vivienda provincial y municipal, los miembros de la Asociación Civil y la Cooperativa de Vivienda ejecutaron su proyecto habitacional. En 1999, al finalizar la primera etapa, las 75 familias ubicadas en el primer sector se mudaron a sus nuevos hogares y desocuparon las tierras del Parque Sur (VidAL ET AL., 2001). 


\section{Conclusión}

Las políticas alternativas del hábitat se incorporaron parcialmente a los planes habitacionales preexistentes, desde los 80. Entre sus modificaciones, las ONG sumaron su trabajo a la cuestión habitacional desarrollando "cadenas de ayuda" con los sectores populares. Con esta metodología, en Rosario, se comenzaron a organizar varias cooperativas de vivienda, como la de Villa Margarita, que recibieron financiación alternativa para sus proyectos de organizaciones religiosas, subvenciones estatales u ONG extranjeras o locales. Así, los miembros de la Cooperativa de Villa Margarita autoconstruyeron sus primeras catorce viviendas. En el caso de la Asociación Civil El Monte, su trabajo barrial se concentró en atender las necesidades inmediatas de sus miembros, alimento y trabajo. Mientras, su compromiso con la autoconstrucción se encontraba más relegado (la Cooperativa de Vivienda La Gloria se organizó en el marco del Programa Arraigo en los 90). El aparente vínculo partidario de esta agrupación con la gestión municipal radical relativizaba su proclamada autoorganización y evidenciaba una marcada influencia de esta esfera estatal en ella. Más allá de esto, ambas organizaciones populares utilizaron las mismas prácticas organizativas al recibir asesoramiento técnico y financiación de ONG y otras instituciones civiles y, a la vez, incorporarse al Movimiento Social Hábitat Popular para emprender el camino al hábitat.

El trabajo barrial previo de estas organizaciones solo se visibilizó con el Programa Arraigo, que les otorgó la propiedad del suelo para construir sus nuevas viviendas e incorporarse a la ciudad. Sin dudas, la experiencia autoconstructiva de Villa Margarita era más antigua y consolidada que la del asentamiento El Monte, pero el Programa Arraigo las incorporó a ambas del mismo modo. Este plan se caracterizó por captar agrupaciones con algún tipo de experiencia en la organización barrial y autoconstructiva. Aquí se observa la "estrategia facilitadora” del Estado Nacional, que solo intervenía en la cuestión legal de acceso al suelo urbano y dejaba en manos de las organizaciones la materialización de las unidades habitacionales. No obstante, la incorporación de estas agrupaciones a los planes y programas de esta política significó para ellas cumplir plazos y condiciones impuestas por el Estado en sus diversas jurisdicciones.

Este nuevo rol del Estado Nacional repercutió en el lugar que la gestión municipal rosarina adquirió en la cuestión habitacional. Si bien los saqueos y el cambio de partido político gobernante influyeron en la relación de la Municipalidad y los barrios, su 
política "estratégica" con una intervención sostenida era creciente. La gestión municipal no solo canalizó recursos y acompañó los proyectos habitacionales, sino que también, a través de su Secretaría de Planificación, intervenía en la ubicación de las nuevas viviendas, como en los casos trabajados aquí. En efecto, el Estado continuaba controlando las condiciones para el acceso al suelo urbano de los sectores populares, aunque estas potestades municipales no se percibían tan evidentes cuando se justificaban con los problemas técnicos estructurales en las periferias. Esto restringió enormemente su autonomía organizativa y la capacidad de reproducción de prácticas sociales y políticas en los barrios rosarinos que comenzaron a encontrarse intervenidos por una creciente presencia municipal.

Sin embargo, las políticas alternativas de vivienda reconocieron el trabajo de las cooperativas como las de Villa Margarita y El Monte y las ayudaron a concretar la construcción de sus hogares. En esta senda, la estrategia metodológica ha permitido (re)construir cómo los reclamos de estas organizaciones, el trabajo de sus cooperativas y la ayuda de los movimientos sociales colaboraron en mejorar la situación habitacional de la periferia rosarina. Aun con grandes condicionamientos, el Estado, en sus múltiples escalas, se vio obligado a gestionar políticas de subsidios habitacionales para la regularización dominial y la producción habitacional en estos barrios.

\section{Referencias bibliográficas}

AA. VV. (1992). Asentamientos irregulares de la Ciudad de Rosario. Características físicas y urbanísticas. Indicadores sociales. Fundación Banco Municipal.

Ballent, A. \& Liernur, F. (2014). La casa y la multitud: Vivienda, política y cultura en la Argentina Moderna. Fondo de Cultura Económica.

Carné, M. (2016). Las villas de emergencia y sus viviendas en las racionalidades políticas de las autoridades socialistas del Departamento del Ejecutivo $\mathrm{Mu}-$ nicipal de Rosario (1989-2007). En Cuaderno Urbano, Vol. 21, N. ${ }^{\circ} 21$, pp. 93-112.

Cravino, M. C. (2006). Las villas de la ciudad. Mercado e informalidad urbana. Los Polvorines: UNGS.

Cravino, M. C. (2012) (Comp.) Repensando la ciudad informal en América Latina. Los Polvorines: UNGS. 
Cravino, M. C.; Fernández Wagner, R. \& Varela, O. (2002).“Notas sobre la política habitacional en el Área Metropolitana de Buenos Aires en los años 90. En Andrenacci, L. (Org.), Cuestión social y política social en el Gran Buenos Aires. Ediciones Al Margen, UNGS.

Cuenya, B. (1992). Políticas habitacionales en crisis: el caso de Argentina. Vivienda, Nueva Época, 3 (3), pp. 36-45.

Cuenya, B. \& Falú, A. (Comp.) (1997). Reestructuración del Estado y política de vivienda en la Argentina. Eudeba, CEA-UBA.

Cuenya, B. (1997). Descentralización y política de la vivienda en la Argentina. En Cuenya, B. \& Falú, A. (Comp.). Reestructuración del Estado y política de vivienda en la Argentina. Eudeba, CEA-UBA.

Dalla Corte, G. (2014). Hacia los 25 años de los saques en la ciudad de Rosario, Argentina. Educación y memoria. HAO, Núm. 33 (invierno, 2014), 7-19.

Del Río, J. P. (2011). El lugar de la vivienda social en la ciudad. Un análisis de las políticas habitacionales desde el mercado de localizaciones intra-urbanas y las trayectorias residenciales de los habitantes. (Tesis de Doctorado), UNLP.

Di Meglio, G. \& Serulnicov, S. (2017). La larga historia de los saqueos en la Argentina: De la independencia a nuestros días. Siglo XXI Editores.

Echeverría Ramírez, M. C. et al. (2009) ¿Qué es el hábitat?: las preguntas por el hábitat. Escuela del Hábitat CEHAP, Facultad de Arquitectura, UNC.

Marengo. M. C. \& Elorza, A. L. (2016). Vivienda social en Córdoba: Efectos en la segregación residencial y el crecimiento urbano (1991-2008). En Revista INVI, N. ${ }^{\circ}$ 86 vol.31 pp.119-144.

Martínez Noriega, R. (1994). Interrelación negociada: Las ONG y el gobierno municipal en Rosario, Argentina. En Reilly, C. (1994), Nuevas políticas urbanas: La ONG y los gobiernos municipales en la democratización latinoamericana. Fundación Interamericana Virginia.

Merklen, D. (1997). Organización comunitaria y práctica política. Las ocupaciones de la tierra en el conurbano de Buenos Aires. Nueva Sociedad N. ${ }^{\circ} 149$, pp.162-177.

Oszlak, O. (1993). El mito del estado mínimo: una década de reforma estatal en la Argentina. Desarrollo Económico, Vol. 42, N. ${ }^{\circ} 168$.

O’Donnell, G. (1976). Reflexiones sobre las tendencias generales del cambio en el Estado burocrático-autoritario. Doc. CEDES/CLACSO, Núm. 1, Buenos Aires. 
Paiva, V. (2008). Cartoneros y cooperativas de recuperadores. Una mirada sobre la recolección informales residuos. AMBA,1999-2007. Prometeo Libros.

Pagnoni, A. (2019). Un repertorio de acciones colectivas urbanas. Los saqueos, el hambre y la vivienda cooperativa en la zona sur de Rosario (1979-1989). Estudios del ISHIR, año 9, N. ${ }^{\circ} 24$.

Salgado, M. (2012). Evolución de las experiencias de cooperativas de vivienda en Rosario, Argentina. En Brassard, M. \& Molina, E. El asombroso poder de las cooperativas. Textos escogidos, Quebec.

Secretaría General de la Coalición Internacional del Hábitat (HIC SG) (2016). Conferencias Hábitat I, II y III (1976-2016), MISERIOR y Fondation Charles Leopold Mayer. http://hic-gs.org/content/HIC_Habitat\%201976\%202016\%20ES.pdf

Vitale, P. (2013). Entre los hechos y los derechos: las políticas públicas de las villas de Buenos Aires. En Bolivar, T. \& Erazo Espinoza, J. (Comp.) Los lugares del hábitat y la inclusión. CLACSO.

Vidal, D. (Coord.); Salgado, M. et al. (2001). Vivienda financiada por el estado en Rosario 1989-1999. UNR Editora.

Wacquant, L. (2010). Castigar a los pobres. El gobierno neoliberal de la inseguridad social. Geisa Editorial.

Turner, J. (1977). Vivienda, todo el poder para los usuarios. Hacia la economía en la construcción del entorno. H. Blume Ediciones.

Zapata, C. (2017). La política porteña bajo la lupa: de los programas de llave en mano a la autogestión del hábitat. Teseo.

Ziss, R. \& Lemke, K. (1988). Vivienda Popular y ayuda mutua. Cooperación para mejorar la situación habitacional de los países en desarrollo. Ministerio Federal Alemán de la cooperación económica.

\section{Fuentes consultadas}

La Capital, 1990-1997.

Rosario/12, 1994. 
